\title{
INSUBORDINAÇÃO: UMA PROPOSTA FUNCIONALISTA PARA O ESTUDO DE (DES)ARTICULAÇÃO DE CLÁUSULAS
}

\author{
Gabriela do Couto BARONI' \\ Violeta Virginia RODRIGUES ${ }^{2}$
}

DOI: http://dx.doi.org/10.21165/gel.v18i3.3145

Resumo: A possibilidade de cláusulas "subordinadas" se materializarem de forma independente recebe tratamento diferenciado em diversas línguas. Em Português, essa materialização envolve dois fenômenos distintos - o desgarramento e a insubordinação. O termo "insubordinação", cunhado por Evans (2007), refere-se ao fenômeno pelo qual cláusulas estruturalmente idênticas às subordinadas são usadas de forma independente, sem a presença de uma principal. A proposta do linguista despertou o interesse de diversos estudiosos que, desde então, têm oferecido diferentes contribuições sobre o tema, como Mithun (2008), Cristofaro (2016), Heine, Kuteva e Kaltenbök (2016) e D'Hertefelt (2018), para citar alguns. No Brasil, Hirata-Vale, Oliveira e Silva (2017), HirataVale (2020) e Rodrigues (2021) também têm se dedicado a analisar o fenômeno. Baseadas no funcionalismo, as pesquisas acerca de cláusulas insubordinadas utilizam como corpus dados reais de fala ou escrita, que podem ser investigados tanto sincronicamente quanto diacronicamente. Além de mostrarmos um panorama a respeito dos estudos sobre insubordinação, assumimos aqui, com base em Cristofaro (2016), que o desengajamento clausal é um subtipo de insubordinação, que sabemos envolver padrões distintos. Como exemplos de insubordinação em português brasileiro, utilizamos dados de pesquisas que temos realizado sobre o tema e que ainda estão em andamento.

Palavras-chave: Desgarramento. Insubordinação. Articulação de cláusulas. Funcionalismo.

\footnotetext{
1 Universidade Federal do Espírito Santo (UFES), Vitória, Espírito Santo, Brasil; gabrielacbaroni@hotmail.com; https://orcid.org/0000-0003-1595-9479

2 Universidade Federal do Rio de Janeiro (UFRJ), Rio de Janeiro, Rio de Janeiro, Brasil; violeta.rodrigues@letras.ufrj.br; https://orcid.org/0000-0003-1789-5675
} 
- Insubordinação: uma proposta funcionalista para o estudo de (des)articulação de cláusulas

\title{
INSUBORDINATION: A FUNCTIONALIST PROPOSAL FOR THE STUDY OF (DES)ARTICULATION OF CLAUSES
}

\begin{abstract}
The possibility of "subordinate" clauses materializing independently receives different treatment in several languages. In Portuguese, this materialization involves two distinct phenomena - detachment and insubordination. The term "insubordination", coined by Evans (2007), refers to the phenomenon whereby clauses structurally identical to subordinate ones are used independently, without the presence of a principal. The linguist's proposal aroused the interest of several scholars who, since then, have offered different contributions on the topic, such as Mithun (2008), Cristofaro (2016), Heine, Kuteva, and Kaltenbök (2016), and D'Hertefelt (2018), to name a few. In Brazil, HirataVale, Oliveira, and Silva (2017), Hirata-Vale (2020), and Rodrigues (2021) have also been dedicated to analyzing the phenomenon. Based on functionalism, research on insubordinate clauses uses real data from speech or writing as corpus, which can be investigated both synchronously and diachronically. In addition to showing an overview of studies on insubordination, we assume here, based on Cristofaro (2016), that clausal disengagement is a subtype of insubordination, which we know involves different patterns. As examples of insubordination in Brazilian Portuguese, we use data from research that we have carried out on the subject and which is still ongoing.
\end{abstract}

Keywords: Detachment. Insubordination. Articulation of clauses. Funcionalism.

\section{Introdução}

Este artigo traz à cena um tema que, nos últimos anos, têm despertado o interesse de linguistas em diferentes partes do mundo: o uso independente, como cláusula principal, de estruturas formalmente idênticas às subordinadas. A esse fenômeno, Evans (2007) denominou insubordinação e, desde então, o termo cunhado pelo autor é usado em referência a essas estruturas que, de marginalizadas, passaram a ser analisadas como integrando processos importantes de mudança linguística.

Em português, cláusulas como "Que seu dia seja lindo" e "Se você puder me ajudar..." são exemplos de insubordinação. Trata-se, respectivamente, de estruturas equivalentes àquelas que a Gramática Tradicional classifica como subordinada substantiva objetiva direta e subordinada adverbial condicional e que, portanto, deveriam vir acompanhadas de suas respectivas principais. O que se verifica, porém, é que o uso insubordinado dessas cláusulas é perfeitamente aceito pelos falantes e não acarreta prejuízos ao entendimento da mensagem. 
As investigações sobre a insubordinação são feitas sob a perspectiva funcionalista e, portanto, têm como objeto de estudo a língua em uso, observada em situações reais de fala ou escrita, em uma abordagem sincrônica ou diacrônica. Desse modo, visando ao estudo da língua em uso, além dos exemplos dos próprios textos revisitados, utilizamos, neste artigo, dados coletados de roteiros de cinema, do Facebook e do aplicativo WhatsApp, que permitem, estes últimos, a mobilização de distintos modos semióticos na constituição de suas postagens, que vão desde a escrita, passando por imagens, áudios e vídeos.

A proposta inicial de Evans (2007) sugere que a insubordinação é especialmente motivada pelo mecanismo de elipse. Nesse processo, considera-se que a cláusula principal foi omitida e precisa ser reconstruída pelo interlocutor por meio de inferências baseadas no contexto. No entanto, pesquisas posteriores à de Evans (2007) constataram que a elipse é apenas um dos mecanismos que pode levar à insubordinação, e o modelo de análise do linguista passou, então, a ser considerado incompleto ou simplista demais por alguns estudiosos, como notam Evans e Watanabe (2016). Entre as proposições subsequentes às de Evans (2007) estão, por exemplo, as de Mithun (2008), de Cristofaro (2016), de Heine, Kuteva e Kaltenbök (2016) e de D'Hertefelt (2018), que apresentam, cada um deles, perspectivas distintas sobre o fenômeno.

Assim, o objetivo principal deste texto é aplicar a dados do Português a proposta de Cristofaro (2016), com base na revisão das linhas gerais percorridas pelas pesquisas relativas à insubordinação. Não se tem a pretensão, pois seria claramente inviável, de mostrar todos os trabalhos feitos até aqui. Espera-se, no entanto, apresentar algumas das principais contribuições e os caminhos que têm sido adotados nas análises, para melhor compreensão de nosso objetivo principal.

A fim de cumprir esse propósito, este artigo encontra-se organizado da seguinte maneira: parte-se, primeiramente, dos trabalhos de Evans (2007) e de Mithun (2008), responsáveis por colocar o tema em pauta. Após, são expostas as contribuições analíticas de Cristofaro (2016). Em seguida, são destacados os estudos do assunto no Brasil, por meio das pesquisas de Hirata-Vale, Oliveira e Silva (2017), Hirata-Vale (2020) e Rodrigues (2021). Por fim, esboçam-se os rumos e as perspectivas de investigação a respeito das insubordinadas, adotando-se, principalmente, a proposta de desengajamento clausal de Cristofaro (2016). Sempre que possível, são estabelecidas correlações entre as discussões e exemplificados usos do fenômeno com dados de investigações em curso das autoras deste artigo. 
- Insubordinação: uma proposta funcionalista para o estudo de (des)articulação de cláusulas

\section{Insubordinação: a proposta de Evans (2007)}

Partindo da alegação de que este é um fenômeno muito mais comum e difundido do que se imagina, Evans (2007) utiliza o termo insubordinação para se referir ao uso, como cláusula principal, de estruturas que, à primeira vista, parecem formalmente subordinadas. O linguista critica o fato de que as cláusulas insubordinadas são, muitas vezes, tratadas como "erros" ou consideradas marginais ou elípticas demais para serem descritas nas gramáticas de referência. Aliás, a motivação de Evans (2007) para o estudo das insubordinadas surge justamente desta "dificuldade": enquanto escrevia uma gramática para a língua aborígene australiana Kayardild, no ano de 1995, o autor se deparou com o desafio de classificar, dentro dos parâmetros gramaticais, cláusulas que eram recorrentemente utilizadas como independentes pelos falantes, mas que possuíam estrutura de subordinadas. A partir de então, passou a observar e a comparar esses usos em diferentes línguas, sistematizando o que veio a chamar, em 2007, de insubordinação.

Para Evans (2007), a insubordinação é fomentada pelo mecanismo de elipse. Partese, portanto, da premissa de que a cláusula principal foi omitida, cabendo ao interlocutor o papel de inferi-la a partir do contexto e, consequentemente, de seu conhecimento de mundo e de sua competência linguística. A insubordinação, como outras mudanças que acontecem na língua, ocorre de maneira gradual. Para esse fenômeno, Evans (2007) propôs o continuum a seguir, que representa, em quatro etapas, a trajetória histórica que leva à formação de cláusulas insubordinadas:

Quadro 1. Trajetória de insubordinação de cláusulas

\begin{tabular}{|l|l|l|l|}
\hline \multicolumn{1}{|c|}{ Subordinação } & \multicolumn{1}{|c|}{ Elipse } & \multicolumn{1}{c|}{$\begin{array}{c}\text { Elipse } \\
\text { convencionalizada }\end{array}$} & $\begin{array}{l}\text { Reanálise como estrutura } \\
\text { de cláusula principal }\end{array}$ \\
\hline $\begin{array}{l}\text { (1) Construção } \\
\text { subordinada }\end{array}$ & $\begin{array}{l}\text { (2) Elipse } \\
\text { da cláusula } \\
\text { principal }\end{array}$ & $\begin{array}{l}\text { (3) Restrição de } \\
\text { interpretação do } \\
\text { material elipsado }\end{array}$ & $\begin{array}{l}\text { (4) Uso convencionalizado } \\
\text { da cláusula originalmente } \\
\text { subordinada como cláusula } \\
\text { principal }\end{array}$ \\
\hline
\end{tabular}

Fonte: Evans (2007, p. 370).

O linguista explica que, no primeiro estágio, estão as cláusulas subordinadas prototípicas, tais como tradicionalmente definidas pelas gramáticas. No segundo estágio, a cláusula principal passa a ser elipsada e a construção subordinada começa a ser usada de forma independente. Neste caso, como explica Evans (2007), qualquer cláusula principal gramaticalmente compatível com a subordinada pode ser "reconstruída" pelo ouvinte. A escolha a respeito de qual cláusula principal deve "preencher" esse espaço é baseada em processos de inferência conversacional. Na etapa seguinte, tem início a 
restrição de interpretação do material elipsado, o que significa que algumas cláusulas, apesar de gramaticalmente aceitas, são convencionalmente excluídas pelos falantes. Essa restrição ${ }^{3}$, conforme o linguista, pode ser mais geral, como no exemplo (1), a seguir, em que a elipse só é aceita em cláusulas afirmativas e entre elas há uma gama de possibilidades, ou mais específica, como em (2), em que, na opinião do autor, a cláusula insubordinada resultante não necessita de contexto linguístico ou situacional para ser compreendida. Os exemplos (1) e (2) foram fornecidos por Evans (2007) com base em Buscha ${ }^{4}$ (1976, p. 276). As traduções são nossas:

(1) If you would maybe like to wash your hands.

[, that would be very nice of you]

[, you can do it here]

*[, you cannot do it $]$

*[, that would not be very nice of you]

Se você quiser lavar as mãos.

[, isso seria muito gentil da sua parte]

[, você pode fazer isso aqui]

*[, você não pode fazer isso]

* [, isso não seria muito gentil da sua parte]

(2) And if I don't get away from her?

[What happen?]

E se eu não me afastar dela?

[O que acontece?]

Por fim, ao atingirem o quarto estágio da trajetória de mudança, as cláusulas insubordinadas são convencionalmente usadas como cláusulas principais. Nessa etapa, segundo Evans (2007), ocorre uma construcionalização da estrutura anteriormente subordinada. Essa construção, agora, possui um significado específico próprio e não é mais possível restaurar o material elipsado.

\footnotetext{
3 É importante deixar claro que a restrição e, por conseguinte, a convencionalização, é específica em cada língua e, portanto, ela tem sentido e é compreendida naquela comunidade de falantes. Em (1) e (2), os exemplos foram extraídos por Evans (2007) do alemão, logo, nessa língua, essas restrições são entendidas da maneira como foram mostradas.

4 Os exemplos de Buscha (1976) estão em alemão. Por uma questão de espaço, optamos por apresentá-los somente em inglês, conforme tradução utilizada por Evans (2007).
} 
- Insubordinação: uma proposta funcionalista para o estudo de (des)articulação de cláusulas

É importante ressaltar que se trata de um processo de mudança gradual, de um continuum. Desse modo, a proposta de Evans (2007) não diz respeito a etapas distintas entre si; ao contrário, elas se sobrepõem e podem, por determinado tempo, coexistir. Isso significa, por exemplo, que uma mesma estrutura pode ser usada pelos falantes como subordinada ou insubordinada até que a mudança atinja o último estágio. Em muitos casos, o estágio final pode, inclusive, não ser atingido, como observa Evans (2007).

Em português brasileiro, o uso de cláusulas volitivas com estrutura de completivas ilustra esta situação: elas ocorrem tanto com a principal, na função de subordinadas objetivas diretas, quanto sem a principal, de forma independente e, portanto, insubordinada. As figuras (1) e (2), a seguir, exemplificam, respectivamente, esses casos:

Figura 1. Post com exemplo de cláusula completiva volitiva

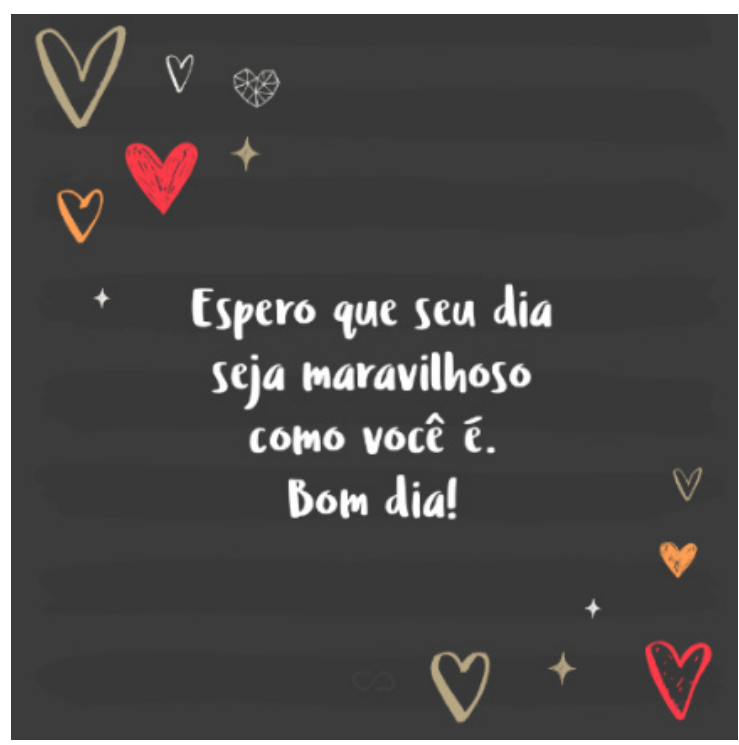

Fonte: $\operatorname{Corpus}^{5}$ de pesquisa das autoras.
Figura 2. Post com exemplo de cláusula volitiva insubordinada

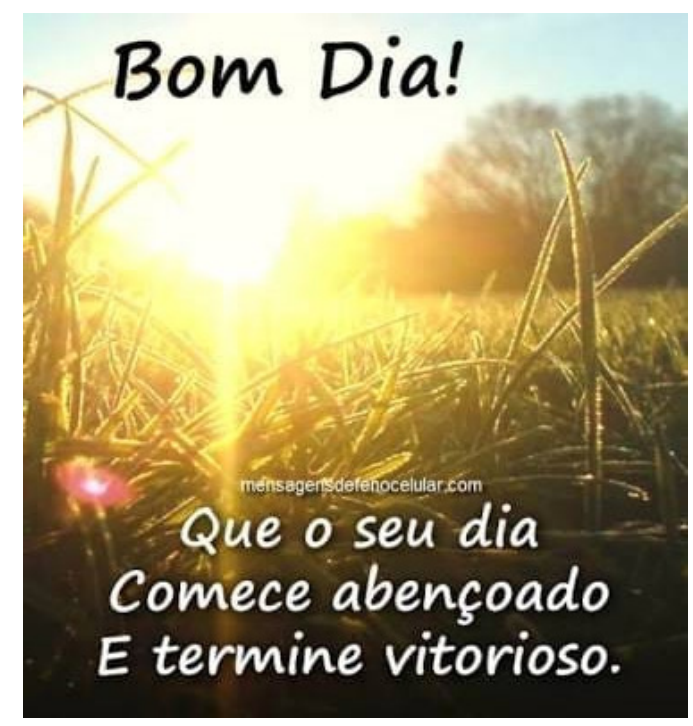

Fonte: Corpus de pesquisa das autoras.

Como se observa nos exemplos mostrados nas Figuras (1) e (2), em português brasileiro, o uso subordinado e o uso insubordinado de estruturas completivas coexistem. No que diz respeito à insubordinada da Figura (2), mesmo havendo, nos termos de Evans (2007), a elipse da cláusula principal, o falante consegue depreender o sentido volitivo da estrutura. Relacionando este exemplo à trajetória de insubordinação proposta por Evans (2007), pode-se afirmar que cláusulas volitivas como “Que seu dia comece abençoado

5 Para fins de pesquisas a respeito de insubordinação de cláusulas e de desgarramento (cf. DECAT, 1999, 2011), as autoras estruturaram um corpus composto por posts veiculados na internet e em redes sociais. Foram considerados como posts (ou postagens) quaisquer mensagens, textos ou imagens publicados nessas redes ou em aplicativos. Para conhecer alguns dos resultados já encontrados nessas pesquisas, consulte Rodrigues $(2019,2021)$. 
e termine vitorioso", da Figura (2), encontram-se entre a segunda e a terceira etapa do processo de mudança, ou seja, há elipse da cláusula principal e, de certa forma, há restrição de interpretação do material que foi elipsado, pois, apesar da possível inferência, por parte do falante, de que se trata de um verbo volitivo, nem todos os verbos desse campo semântico tenderiam a ocupar o espaço deixado pela elipse. O corpus estruturado pelas autoras, por exemplo, revela que verbos como esperar, desejar e querer aparecem nas postagens coletadas em que a cláusula principal é utilizada, como acontece na Figura (1). Por outro lado, não foram encontrados nessas postagens outros verbos volitivos, como pretender, ambicionar, anelar e aspirar. Desse modo, é mais provável ${ }^{6}$ que o falante, ao inferir o sentido de cláusulas como "Que seu dia comece abençoado e termine vitorioso", suponha ter havido ali a supressão de verbos como esperar, desejar e querer, e não dos demais volitivos anteriormente citados.

Evans (2007) ressalta que a trajetória proposta por ele alterna entre a abertura e o fechamento do papel da pragmática. Conforme explica, primeiramente, uma cláusula subordinada torna-se independente e disponível para interpretações pragmáticas; nesta fase, ela se torna "menos gramatical". Na segunda fase, porém, ocorre a despragmatização, pois a cláusula recém-independente adquire um significado construcional mais específico.

Nesse sentido, para o linguista, os estudos sobre insubordinação importam às tipologias funcionais "interacionistas" que não objetivam substituir as descrições estruturais pelas funcionais, mas, antes, examinam as maneiras pelas quais diferentes funções, entre elas a interpretação pragmática, interdependem de estruturas particulares da linguagem. Um ponto também interessante no que diz respeito à insubordinação, segundo Evans (2007), é que ela se move na direção oposta a outros processos de mudança morfossintática, como a gramaticalização. Esta última, como amplamente defendido na literatura funcionalista ${ }^{7}$, é um processo unidirecional que caminha da pragmática para a sintaxe e da sintaxe para a morfologia. Ou, em outras palavras, que leva uma unidade "menos gramatical" a tornar-se "mais gramatical". Uma das consequências da gramaticalização, portanto, é que as construções "pragmáticas" paratáticas frouxas tornam-se sintáticas como cláusulas subordinadas, como explica Evans (2007). Com a insubordinação, por outro lado, ocorre justamente o contrário, uma vez que ela recruta estruturas de cláusula principal a partir de cláusulas subordinadas, como também nota o autor.

6 Estamos nos referindo a esta como uma situação possível, pois se trata de pesquisa ainda em andamento. Até o momento, as análises indicam esse resultado.

7 Estamos nos referindo aqui ao funcionalismo de orientação norte-americana. 
Sem explicitarquais seriam os motivos, Evans (2007) afirma que nem todas as cláusulas subordinadas podem ser usadas com a cláusula principal elipsada. Isso significa, portanto, que algumas cláusulas, embora subordinadas, não são candidatas à insubordinação. Em português brasileiro, por razões que também precisam ser investigadas, é possível observar que algumas cláusulas volitivas, em certos contextos, não permitem a elipse de sua principal, como demonstram os exemplos criados por nós a seguir:

(3a) Quero/desejo/espero que você seja feliz onde estiver.

(3b) Que você seja feliz onde estiver.

(3c) Seja feliz onde estiver.

(4a) Quero/espero/ordeno que você leve o lixo!

(4b) * Que você leve o lixo!

(4c) Leve o lixo!

(5a) Quero/espero/ordeno que você arrume o quarto.

(5b) *Que você arrume o quarto.

(5c) Arrume o quarto.

Nossa análise a respeito de insubordinadas volitivas, ainda em andamento, sugere haver alguma relação, que necessita ser melhor compreendida, entre o modo verbal e o uso independente de cláusulas subordinadas. Como se depreende a partir dos exemplos de (3a) a (5c), quando a cláusula complexa permite uma paráfrase no imperativo que exprime desejo, a elipse da principal é admissível. Por outro lado, se essa paráfrase indica uma ordem, a elipse da principal torna-se menos plausível, impedindo, assim, que haja insubordinação.

Evans (2007) deixa claro que sua pesquisa inicial é heurística e que sua preocupação é explorar construções que tendem a ser marginalizadas na análise e descrição linguísticas. Seu objetivo, como destaca, é incentivar os linguistas "a levarem essas construções mais a sério", considerando que a insubordinação é um fenômeno importante em razão da direção incomum percorrida pela mudança diacrônica: da cláusula subordinada à principal, da morfossintaxe ao discurso e, em seu estágio inicial, da gramática à pragmática.

Conforme Evans e Watanabe (2016), desde a proposição inicial de Evans (2007), diversos pesquisadores passaram a analisar a insubordinação em diferentes línguas, encontrando novas funções para as estruturas resultantes da insubordinação ou questionando aspectos do modelo original. Como ressaltam os autores, os estudos subsequentes ao de Evans (2007) apresentam contribuições como: 
(i) maior atenção à gramática de interação;

(ii) melhor incorporação da prosódia às análises ${ }^{8}$;

(iii) uso de dados de fala espontânea em vez de dados de fala induzida;

(iv) diferente perspectiva sobre a insubordinação a partir da adoção da díade conversacional como entidade geradora de estruturas gramaticais, em vez de levar em conta apenas o falante isoladamente.

\section{A proposta de extensão funcional de Mithun (2008)}

Do mesmo modo que Evans (2007), Mithun (2008) assevera que a insubordinação, embora já tenha sido constatada em diversas línguas, é um fenômeno que recebe relativamente pouca atenção. Em suas análises, a linguista atesta a presença de padrões semelhantes de insubordinação em línguas não relacionadas entre si e reforça a necessidade de compreensão desses padrões para que se possa elucidar esse tipo de mudança linguística.

Para Mithun (2008), a insubordinação é um dos processos ${ }^{9}$ nos quais se observa uma extensão funcional de marcadores de dependência gramatical do nível sintático da cláusula para domínios discursivos e pragmáticos mais amplos. Como consequência, segundo explica, pode haver uma remodelação da estrutura básica da cláusula subordinada, que passa a ser usada de forma independente.

A análise de Mithun (2008) a respeito da insubordinação está pautada, principalmente, em narrativas orais da língua atabascana ${ }^{10}$ Navajo, do sudoeste americano, e da língua esquimó Yup'ik, do sudoeste do Alasca. Nessas narrativas, a linguista detectou o uso sistemático de cláusulas "subordinadas" sem a presença da matriz, ou seja, de insubordinadas.

De acordo com Mithun (2008), embora a concepção de insubordinação de Evans (2007) esteja relacionada ao domínio da própria cláusula e à elipse da matriz, nas línguas investigadas foi possível notar uma relação da cláusula insubordinada com um contexto pragmático mais amplo ou com ideias de um tópico mais abrangente de discussão. Nesse

8 Rodrigues e Silvestre (2014), Rodrigues e Fontes (2018), Rodrigues e Silvestre (2019) e Rodrigues e Mallmann (2020) incorporaram análises prosódicas para descrever o fenômeno do desgarramento em Português.

9 Para a autora, há outros processos de mudança - e não apenas a insubordinação - que envolvem a extensão funcional. Por uma questão de espaço e escopo, eles não serão discutidos aqui.

10 As línguas atabascanas são um grupo de línguas faladas por nativos americanos da América do Norte. 
sentido, para a estudiosa, essas cláusulas são dependentes, mas não necessariamente subordinadas da maneira como as cláusulas complementares são.

Com base nas averiguações feitas, Mithun (2008) alega que, em Navajo e em Yup'ik, o que acontece não é apenas a elipse da principal, conforme a proposta de Evans (2007), mas, sobretudo, um processo discursivo por meio do qual uma cláusula antes ligada, pela sintaxe, a uma principal, passa a ter seu funcionamento avaliado em um nível textualdiscursivo. Em outras palavras, segundo a linguista, a função subordinativa é estendida, ou seja, a dependência deixa de ser entre orações dentro de um período para ser entre orações dentro de um contexto mais amplo. Assim, podemos dizer que se extrapola o nível sentencial. O exemplo a seguir, coletado por Mithun (2008, p. 96) em Yup'ik, ilustra a afirmação da autora. A tradução é nossa:

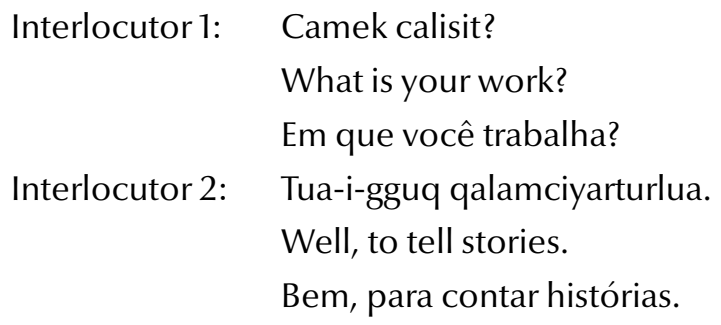

Neste exemplo, para Mithun (2008), a insubordinada produzida pelo segundo interlocutor está diretamente relacionada à fala do primeiro, pois é uma resposta a ela. Refere-se, portanto, ao contexto, por meio do qual a principal pode ser recuperada. Como também explica a linguista, as insubordinadas podem, dessa forma, estar relacionadas a comentários, perguntas, respostas e comandos numa situação de interação. Podem, ainda, ser usadas pelo falante para dar contribuições a falas anteriores à sua, mostrandose, desse modo, associadas aos turnos da conversa.

Também por meio do mecanismo de extensão funcional, os falantes estabelecem uma semelhança entre os contextos de uso da cláusula insubordinada e os contextos originais de ocorrência da cláusula subordinada. Em razão disso, de acordo com Mithun (2008, 2019), a insubordinada não precisa, necessariamente, estar ancorada em uma sentença superordenada, mas pode, em vez disso, ser avaliada em uma conjuntura mais ampla. Seu contexto, como esclarece a autora, é a situação do discurso. O exemplo a seguir, coletado por Mithun (2016, p. 316) em Barbareño Chumash, língua indígena da Califórnia, ilustra esse caso. Nele, o falante faz uma avaliação complementar ao que havia proferido antes, recorrendo, para isso, a uma insubordinada. As traduções são nossas: 
When you are lying down at night out in the woods, you see eyes surrounding you, looking at you.

It is spooky.

Quando você está deitado à noite na floresta, você vê olhos ao seu redor, olhando para você.

É assustador.

Mithun (2008), no entanto, ressalta que os mecanismos que levam à extensão funcional sugerida por ela são, de certo modo, mais abstratos do que a elipse proposta por Evans (2007). A dificuldade em se esclarecer as motivações que levam à insubordinação, segundo a autora, reside no fato de que nunca é necessário que uma cláusula matriz seja omitida, mas os falantes, entretanto, recorrem a esse tipo de uso. Uma justificativa para isso, consoante Mithun (2008), é que as formas insubordinadas tendem a ser menos assertivas do que suas correspondentes completas. Os falantes, então, tenderiam a recorrer a essas formas em contextos nos quais a atenuação ou a baixa assertividade podem estar presentes.

A pesquisa de Mithun (2008), assim como a de Evans (2007), adota uma perspectiva diacrônica. Os dois autores foram os primeiros a se dedicarem ao tema da insubordinação tal como ele tem sido estudado hoje. Na seção seguinte, outra concepção sobre o assunto será abordada, dessa vez sob a visão de Cristofaro (2016) e que foi muito importante para nossa análise.

\section{A proposta de desengajamento clausal de Cristofaro (2016)}

Assim como Evans (2007) e Mithun (2008), Cristofaro (2016) afirma que as origens da insubordinação, isto é, os mecanismos e as motivações subjacentes ao fenômeno, são relativamente pouco conhecidos. Em sua opinião, as cláusulas insubordinadas se desenvolvem a partir de mecanismos de naturezas distintas e que não se aplicam exclusivamente à insubordinação, como a elipse, a reanálise e a extensão, esses dois últimos, por exemplo, presentes também nos processos de gramaticalização.

Para Cristofaro (2016), os trabalhos de Evans (2007) e de Mithun (2008) não são suficientes para dar conta dos diferentes tipos de padrão de insubordinação e carecem de uma proposição mais abrangente no que diz respeito às possíveis construções de origem desses padrões. Com base nessas alegações, a linguista propõe que se acrescente às análises de insubordinação o mecanismo de desengajamento clausal, ao lado da elipse e da extensão funcional propostos por Evans (2007) e por Mithun (2008), respectivamente. 
- Insubordinação: uma proposta funcionalista para o estudo de (des)articulação de cláusulas

De acordo com Cristofaro (2016), por meio do desengajamento clausal, as cláusulas que apresentam algumas características de cláusulas independentes tornamse desengajadas, desconectadas, de uma cláusula coocorrente ${ }^{11}$, fazendo com que elas sejam usadas separadamente, de forma insubordinada. A estudiosa explica que o desengajamento clausal é usado, por exemplo, para introduzir um novo tópico no discurso ou para reelaborar um tópico introduzido anteriormente na conversa. Para Cristofaro (2016, p. 85), a fala a seguir representa um caso de desengajamento clausal em língua italiana. A tradução é nossa e os grifos são da autora:

No, perché poi questo workshop sembra interessante.

Não, porque esse workshop parece interessante.

Contexto: [A cláusula] "No perché poi questo workshop sembra interessante" foi proferida em referência a uma conversa realizada na noite anterior sobre um workshop do qual o orador decidiu participar, apesar das dúvidas iniciais.

Cristofaro (2016) assevera que cláusulas como as do exemplo (8), embora consideradas insubordinadas, não se referem a nenhum estado de coisas que possa ser recuperado por meio de uma cláusula principal elíptica, como propõe Evans (2007). Do mesmo modo, para a linguista, elas também não apresentam propriedades pragmáticas resultantes de um processo de extensão de contextos de uso da cláusula, como preconiza Mithun (2008). Cláusulas insubordinadas como a mostrada em (8) são, segundo Cristofaro (2016, p. 399), motivadas pelo mecanismo de desengajamento clausal e se constituem como unidades "completamente autônomas" no que se refere aos aspectos sintáticos, semânticos, pragmáticos e prosódicos, uma vez que se configuram como afirmações à parte, com entonação própria. Além disso, como explica a autora, essas insubordinadas não estão relacionadas a algum item específico de uma cláusula coocorrente, mas sim elaboram todo o discurso ou algum tópico geral do discurso.

Entretanto, conforme Cristofaro (2016), o uso desse padrão de cláusulas é possivelmente originado de contextos em que a cláusula coocorrente está presente - e não ausente, como acontece em (8). Nesses contextos, cláusulas estruturalmente semelhantes às subordinadas apresentam uma notável independência em relação à sua coocorrente, visto que possuem entonação própria e são expressas depois de uma pausa ou de algum trecho de material intermediário e, não dificilmente, por outro interlocutor. Na maioria das vezes, essas insubordinadas têm o papel de reabrir o turno da conversação

11 Cristofaro (2016) não declara explicitamente o que está sendo chamado de "cláusula coocorrente". Pela leitura do texto, depreende-se que se trata de cláusulas que estão no mesmo contexto em que a insubordinada está sendo usada. Essas cláusulas se "conectam" às insubordinadas no que se refere ao sentido ou à motivação para o que está sendo declarado e são estruturalmente semelhantes a uma cláusula principal. 
para reelaborar o que foi dito. Consoante Cristofaro (2016), isso provavelmente acontece porque o ouvinte não atingiu a compreensão esperada pelo falante no turno anterior. Esse falante, então, recorre a uma insubordinada para realçar as motivações para o estado de coisas descrito por ele em sua primeira fala. O exemplo a seguir, fornecido por Cristofaro (2016, p. 400) também para o italiano, ilustra a explicação da autora. As traduções são nossas:

$$
\begin{aligned}
& \text { A: Ordino uma spesa. } \\
& \text { B: Ok. } \\
& \text { A: Perché abbiamo proprio finito la pasta. }
\end{aligned}
$$

A: Vou agendar uma entrega de supermercado.

B: Ok.

A: Porque nós realmente ficamos sem massa.

Em (9), como se observa, o falante A comunica ao falante B que irá pedir compras no supermercado. O falante B responde com um "Ok", concordando com a afirmação. O falante A, no entanto, recorre a uma insubordinada - Porque nós realmente ficamos sem massa - com o aparente intuito de justificar ou completar a informação anterior dada por ele.

Para Cristofaro (2016), cláusulas insubordinadas como a usada em (9), que demonstram relativa independência em relação às suas coocorrentes, possibilitam que os interlocutores as reinterpretem como unidades autônomas capazes de formular um tópico geral, e não apenas uma cláusula específica. Essas cláusulas passam, então, a ser usadas com a mesma função, mas agora sem a presença necessária de uma cláusula específica ou trecho do discurso ao qual possam se referir. Esse processo é o que Cristofaro (2016) chama de desengajamento clausal.

Cristofaro (2016) admite que o desengajamento clausal é semelhante à extensão funcional proposta por Mithun (2008), uma vez que os dois mecanismos preconizam a expansão dos contextos de uso de determinados tipos de cláusulas. Por outro lado, como afirma, difere-se da concepção de elipse de Evans (2007), porque não diz respeito à supressão de partes da construção de origem.

Embora a proposição de Cristofaro (2016) se assemelhe à de Mithun (2008) no aspecto citado, há, também, como defende a linguista, uma questão que as distingue: o desengajamento clausal origina-se de um desligamento orientado pelo contexto, que permite que uma cláusula estruturalmente semelhante a uma subordinada se separe de sua cláusula coocorrente e seja usada pelo falante para introduzir um novo tópico de 
- Insubordinação: uma proposta funcionalista para o estudo de (des)articulação de cláusulas

discurso, relacionado ao conhecimento prévio compartilhado pelo ouvinte. Na extensão funcional, por sua vez, os falantes estabelecem uma semelhança entre as cláusulas subordinadas em geral e alguns tipos de cláusulas independentes. Nesse último caso, conforme explica Cristofaro (2016), a insubordinada está conectada ao discurso como um todo, e não especificamente a alguma cláusula principal ausente ou elipsada. A extensão funcional, portanto, é motivada pela similaridade entre o antigo e o novo contexto de ocorrência da subordinada, independentemente se esses contextos envolvem ou não a presença de uma cláusula principal, como ressalta a autora.

Consoante Cristofaro (2016), um dos desafios atinentes ao estudo das insubordinadas é identificar a fonte exata dessas cláusulas, uma vez que elas podem se desenvolver a partir de mecanismos diferentes, bem como podem ter origem em diferentes contextos e construções. De acordo com a linguista, a elipse, por exemplo, pode ter como motivação o fato de o material elipsado ser comunicativamente periférico, muito provavelmente porque ele pode ser recuperado pelo contexto. Assim, como esclarece Cristofaro (2016), é possível, então, que, entre os vários contextos semanticamente compatíveis com a cláusula insubordinada resultante, essas cláusulas se desenvolvam a partir daqueles em que o material elipsado é mais facilmente inferível ou comunicativamente mais periférico e, por essa razão, mais propenso a ser deixado de fora. Contribui, ainda, para a elipse, segundo a estudiosa, a frequência de uso da construção fonte, uma vez que a repetição é um dos fatores que levam à omissão do material linguístico, conforme preconiza, por exemplo, Bybee (2016). Geralmente considerada como o principal mecanismo que leva à insubordinação, a elipse, segundo Cristofaro (2016), também envolve um processo metonímico por meio do qual parte de uma oração complexa (a subordinada) assume o significado originalmente associado à construção como um todo, enquanto outra parte (a principal) é suprimida, abandonada.

Por outro lado, como também orienta Cristofaro (2016), a extensão funcional e o desengajamento clausal são mais baseados no que Bybee, Perkins e Pagluica (1994) denominam generalização, um processo por meio do qual propriedades específicas do contexto em que uma construção é originalmente usada tornam-se proeminentes com o passar do tempo e levam a uma expansão dos usos dessas construções para outros contextos que apresentem propriedades semelhantes. Segundo a linguista, todas essas considerações reforçam a hipótese de que a insubordinação pode não ser um fenômeno unificado, mas sim o resultado de vários processos distintos. Esse é o caso, por exemplo, das insubordinadas condicionais, como explica Cristofaro (2016). Com base na concepção da autora, o uso de insubordinadas para solicitações indiretas, como a mostrada em (10), é resultado de elipse. No entanto, em contextos como o de (11), a seguir, o que ocorre é um desengajamento clausal. Os exemplos são nossos: 
(10) Se você puder me ajudar, por favor.

(11) Eu quero dois pedaços dessa torta. Se ela tiver sido feita hoje.

Na seção seguinte, serão mostradas as pesquisas de Hirata-Vale, Oliveira e Silva (2017), Hirata-Vale (2020) e Rodrigues (2021), que, no Brasil, foram as primeiras a lançar o olhar sobre a insubordinação.

\section{As pesquisas de Hirata-Vale, Oliveira e Silva (2017), Hirata-Vale (2020) e Rodrigues (2021)}

Hirata-Vale, Oliveira e Silva (2017) realizam um estudo sincrônico e qualitativo de insubordinadas condicionais e completivas em português brasileiro, utilizando, para isso, dados coletados em corpora de acesso gratuito no português do Brasil, em redes sociais e em pesquisas no Google. Em relação às condicionais, as autoras recorrem à proposta de Evans (2007) e afirmam que as insubordinadas analisadas resultam de uma convencionalização de uso pelos falantes, não sendo necessária, por esse motivo, a presença da principal. Quanto às funções desempenhadas por essas cláusulas, asseveram que elas podem ser usadas de maneira intersubjetiva para expressar uma "instrução" do falante para o interlocutor e para ampliar ou generalizar os significados de enunciados precedentes. Em ambos os casos, trata-se, conforme alegam, de estratégias de polidez. O exemplo a seguir, fornecido por Hirata-Vale, Oliveira e Silva (2017, p. 34), ilustra um uso de insubordinada condicional em que a estratégia de polidez é aplicada pelo falante na sugestão feita ao ouvinte. Os grifos são das autoras:

(12) todo mundo q fez me falou q era lah, se quiser ligar pra confirmar. Rua: BRASIL bem no inicio, o pessoal ai de penapolis tem a lista telefonica daki, é bem no começo OSCAR MOTOS (Internet)

Entre outras funções exercidas pelas insubordinadas condicionais estão, consoante Hirata-Vale, Oliveira e Silva (2017, p. 35), aquelas relacionadas à expressão subjetiva das atitudes do falante, tais como, desejos, crenças e avaliações. O exemplo a seguir, citado pelas estudiosas, demonstra esse tipo de caso. Os grifos são das autoras:

RECEPCIONISTA: [...] Vocês nem cara de bandido tem. Se eu encontrasse com um de vocês num lugar... assim... Num baile, por exemplo, eu... CABELEIRA: Ê mulher chata!

No que tange às insubordinadas completivas, Hirata-Vale, Oliveira e Silva (2017) declaram que essas cláusulas realizam funções discursivas e funcionais e que seus usos expressam ordens, direções e desejos (manifestados por meio de construções imperativas), avaliações e comentários (via construções exclamativas) e elaborações (feitas por meio de 
- Insubordinação: uma proposta funcionalista para o estudo de (des)articulação de cláusulas

construções conectivas). De acordo com Hirata-Vale, Oliveira e Silva (2017), a função das construções conectivas é elaborar ou completar o que havia sido dito pelo falante em um turno anterior, como mostram no exemplo a seguir. Os grifos são das autoras:

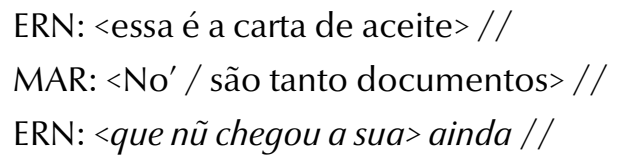

Como se observa em (14), a cláusula destacada, que Hirata-Vale, Oliveira e Silva (2017) denominam construção conectiva, corresponde ao que Cristofaro (2016) trata como desengajamento clausal e se assemelha, em termos de função, àquela apresentada no exemplo (9). Hirata-Vale, Oliveira e Silva (2017), no entanto, argumentam que a cláusula em (14) ainda revela alguma dependência em relação a uma informação anterior do texto e, por essa razão, não seria uma insubordinada prototípica, nos termos de Evans (2007), mas sim um caso de extensão funcional, conforme proposta de Mithun (2008).

Hirata-Vale (2020) dá prosseguimento ao estudo de insubordinadas completivas, com foco, desta vez, nas subjetivas-modais, por meio das quais o falante manifesta sua atitude subjetiva em relação à proposição. Novamente, os corpora utilizados são de língua falada e a análise é sincrônica. A linguista chama essas insubordinadas de construções completivas insubordinadas $(\mathrm{CCl})$ e afirma que, quanto ao aspecto formal, elas são marcadas com o modo subjuntivo, têm natureza exclamativa ou optativa/hortativa e seus sujeitos são de terceira pessoa do singular ou plural. Alega, ainda, que as $\mathrm{CCl}$ resultam do processo de extensão funcional e, por essa razão, expressam relações que extrapolam o nível da oração, devendo, por isso, ser avaliadas apenas discursivamente.

A abordagem utilizada por Hirata-Vale (2020) é construcional-interacional, com base, sobretudo, em Sansiñena (2015) e Gras (2016). Nessa perspectiva, são levados em conta os aspectos subjetivos e intersubjetivos das construções analisadas, visando a observar o papel que elas desempenham nas interações verbais. O exemplo a seguir é mostrado por Hirata-Vale (2020, p. 307) para ilustrar um caso de insubordinada subjetivamodal. Os grifos são da autora:

(15) [...] mas já que estamos nos casando de verdade e oficialmente, que venham as alianças! Mas que venham em ouro branco... porque alianças tudo bem, mas douradas já é demais! (CdP)

De acordo com a linguista, em (15), o modo subjuntivo contribui para uma avaliação subjetiva-modal da insubordinada destacada, uma vez que indica um desejo, por parte do falante, de que a situação apresentada se concretize: que venham as alianças! Para Hirata-Vale (2020), em português brasileiro, as construções completivas insubordinadas 
resultam da extensão funcional do domínio de atuação da conjunção integrante, que passa a desempenhar funções para além do nível da cláusula. Em razão disso, segundo afirma, essa conjunção deixa de atuar como um "subordinador" e adquire outras funções, de cunho discursivo.

Ao analisar o uso independente de cláusulas formalmente subordinadas, Rodrigues (2021) propõe uma distinção entre desgarramento e insubordinação. O termo desgarramento foi cunhado por Decat $(1999,2011)$ para designar estruturas que, apesar de classificadas como subordinadas e dependentes pela Gramática Tradicional, são usadas, tanto na linguagem oral como na linguagem escrita, de maneira "solta", isolada, constituindo, portanto, um enunciado independente.

Para Decat (2011), as cláusulas desgarradas consistem em uma unidade informacional, ou idea unit, conforme concepção de Chafe (1980). Uma unidade de informação, na visão de Chafe (1980), corresponde a um "jato de linguagem" que carrega em si toda a informação que pode ser "manipulada" pelo falante em um único foco ou estado de consciência.

As cláusulas mais propícias ao desgarramento são, segundo Decat (2011), as adverbiais e as relativas apositivas, já que essas, por não serem argumento de um item lexical, não estão estruturalmente integradas à cláusula matriz. Por outro lado, consoante a linguista, as completivas estão fortemente vinculadas à matriz e formam, junto com essa, uma unidade informacional. Desse modo, como alega Decat (2011), as completivas somente se "desgarram" se estiverem em sequenciação parafrástica, ou seja, se uma estrutura sintática idêntica já tiver sido usada de modo "encaixado" anteriormente, no mesmo texto. O exemplo a seguir ilustra o que, para Decat (2011), seria um caso de desgarramento de completivas em sequência parafrástica: 
- Insubordinação: uma proposta funcionalista para o estudo de (des)articulação de cláusulas

Figura 3. Post com exemplo de completivas desgarradas

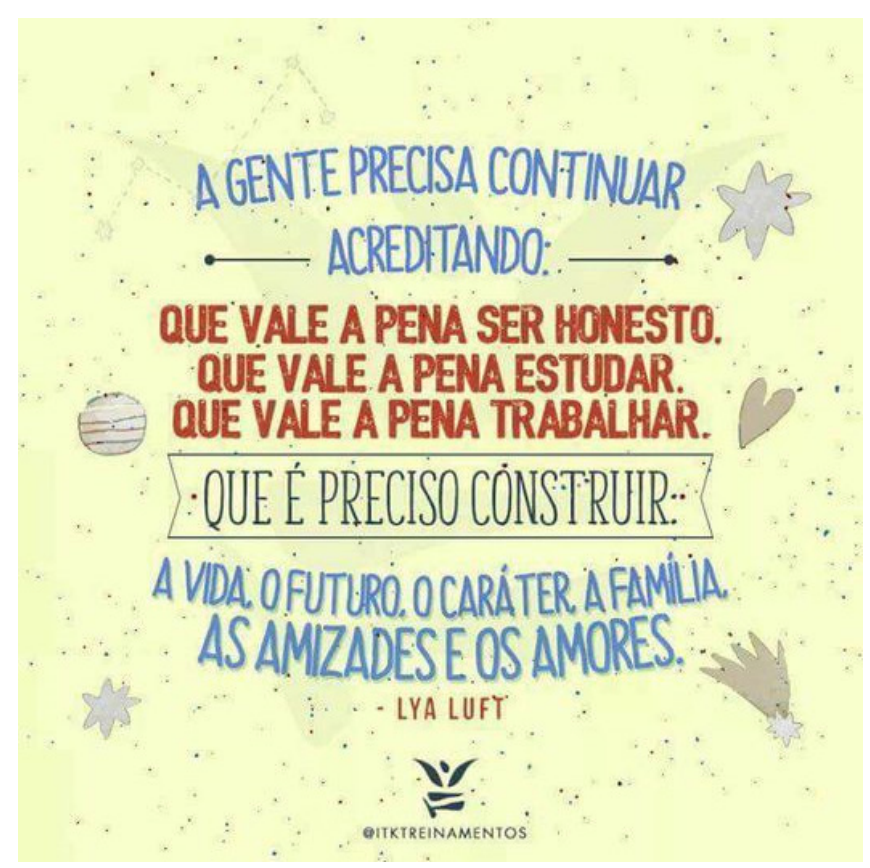

Fonte: Corpus de pesquisa das autoras.

Com base em Decat (1999, 2011), Rodrigues (2021) ratifica que, em português brasileiro, há cláusulas circunstanciais desgarradas e relativas apositivas desgarradas. Especificamente no que se refere às completivas, no entanto, Rodrigues (2021) as distingue em completivas desgarradas - subdivididas ${ }^{12}$ em contextuais, cotextuais e inerentemente pragmáticas -, completivas não desgarradas e completivas insubordinadas. A linguista, portanto, amplia a classificação de Decat $(1999,2011)$, ao mesmo tempo em que diferencia desgarramento e insubordinação em suas análises. Rodrigues (2021, p. 63) denomina desgarradas as completivas que vêm acompanhadas de algum material linguístico recuperável no discurso adjacente, como ilustra o exemplo a seguir:

12 Por uma questão de espaço, a classificação proposta por Rodrigues (2021) para as cláusulas desgarradas não será tratada aqui. Para mais detalhes, consulte Rodrigues (2019) e, também, Rodrigues (2021). 
Figura 4. Post com exemplo de completiva desgarrada

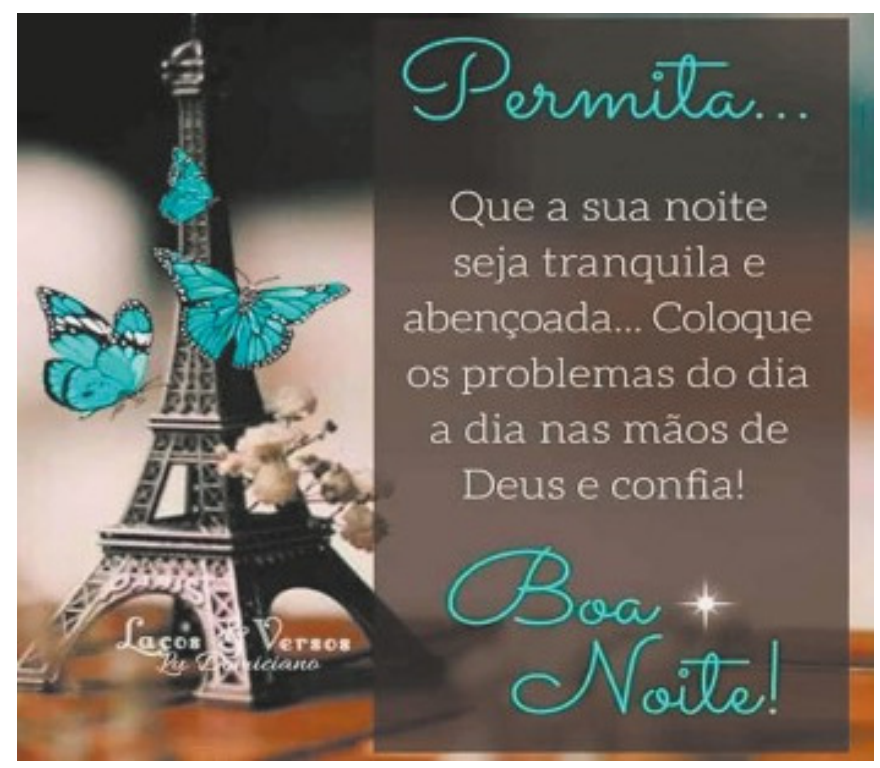

Fonte: Rodrigues (2021, p. 63).

A linguista explica que, neste exemplo, a desgarrada Que a sua noite seja tranquila e abençoada... relaciona-se ao SV permita, do qual se separa por meio de reticências. Por sua vez, Rodrigues (2021, p. 62) considera como insubordinadas as completivas que ocorrem sem a presença de material linguístico precedente, conforme demonstra o exemplo a seguir:

Figura 5. Post com exemplo de completiva insubordinada

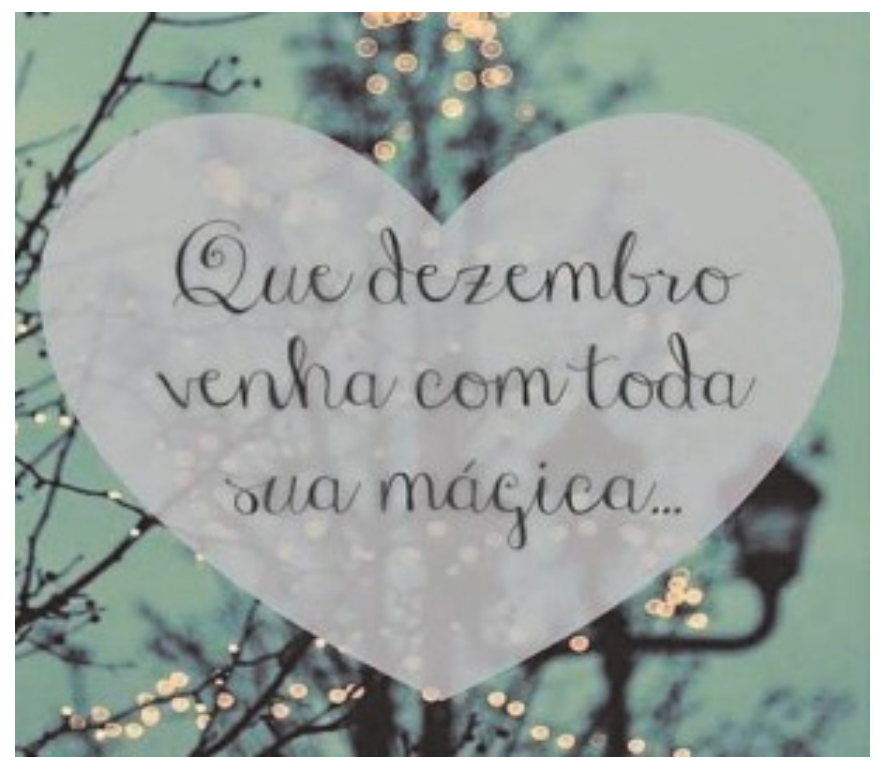

Fonte: Rodrigues (2021, p. 62). 
A estudiosa explica que, nesse exemplo, a insubordinada "Que dezembro venha com toda sua mágica..." expressa o desejo do escrevente, ainda que a cláusula não venha precedida de material linguístico indicativo desse desejo. A completiva insubordinada, segundo Rodrigues (2021), funciona como unidade informacional e, geralmente, é composta de sete a nove palavras. Sua interpretação, como afirma, é feita inferencialmente, baseada no conhecimento de mundo dos falantes na situação comunicativa. No que tange aos aspectos formais das completivas insubordinadas, Rodrigues (2021) declara que elas podem ser representadas por QUE + SN + Subjuntivo, como é possível constatar no último exemplo citado.

A análise de Rodrigues (2021) é sincrônica e seu corpus é constituído, sobretudo, por postagens coletadas no Facebook. Como se observa, os estudos a respeito da insubordinação ainda são incipientes no Brasil e, assim como também acontece com linguistas de outras partes do mundo, muitas ainda são as questões a serem observadas e analisadas pelos pesquisadores que têm se debruçado sobre o fenômeno no país.

\section{Insubordinação: uma proposta de análise a partir do desengajamento clausal}

O quadro teórico apresentado permite-nos evidenciar a importância do cotexto e contexto de uso das cláusulas desgarradas e insubordinadas em situações comunicativas as mais diversas. Além disso, possibilita, ainda, que se repense a própria natureza da independência, autonomia das estruturas desgarradas e insubordinadas - se semântica, pragmática, prosódica.

No que se refere especificamente às insubordinadas, foco deste artigo, conforme visto, estas podem se originar de diferentes contextos. Como visto também, a maioria dos trabalhos incide sobre a modalidade falada, o que não é o nosso caso. Isso dificulta ainda mais a aplicação dos aspectos teóricos arrolados, principalmente se considerarmos que estamos levando em conta dados de língua escrita das redes sociais, que tem suas especificidades.

A proposta de desengajamento clausal de Cristofaro (2016), que não adota a elipse, como Evans (2007), mas a relação da insubordinada com todo um trecho do discurso ou um tópico discursivo geral, ajuda bastante a explicar estruturas que ficariam sem análise na língua escrita. Num sentido específico, quando se fala de desengajamento clausal na língua falada, pressupõem-se atos de falas diferentes e, na língua escrita, encontramos uma correspondência com sequências dialógicas em textos narrativos, como é o caso 
dos roteiros de cinema ${ }^{13}$. Nos fragmentos de texto a seguir, destacam-se, respectivamente, duas insubordinadas circunstanciais - uma final introduzida por para e uma comparativa introduzida por como.

MARGHERIT: Você pode andar mais devagar?

ROBERTO CARLOS: Pra quê?

MARGHERIT: Para conversar um pouco mais...

Roberto continua andando rápido.

(O contador de histórias - 2009)

(17)

ANA (AINDA PROCURANDO-O COM O OLHAR): Ele queria; só não queria mostrar que queria; os gatos são assim...

MARTÍN: Como você.

ANA: Como eu, não! Como você...

(Jogo Subterrâneo - 2010)

As insubordinadas destacadas em (16) e (17) colaboram para complementar o discurso de um personagem em relação ao do outro, simulando uma situação comunicativa próxima à de uma conversação, embora seja um texto escrito. Nisso não há nenhuma novidade, o que chama atenção são as relações semânticas e os conectores usados para indicá-las. Tal surpresa deve-se ao fato de, nos trabalhos revisitados sobre insubordinação, mencionarem-se mais frequentemente se condicional e que completivo.

Como se percebe, essa análise baseia-se numa estrutura diádica. Adaptando-se essa ideia para a linguagem das redes sociais e partindo do pressuposto de que todo texto falado ou escrito pressupõe dialogismo, na postagem a seguir, mesmo não havendo uma estrutura prototípica de diálogo, como visto antes nos fragmentos de roteiros, se estabelece um diálogo entre o escrevente e o leitor da postagem. A insubordinada circunstancial introduzida por quando, manifestando a relação semântica de simultaneidade, permite uma análise em que se pressupõe um diálogo entre a imagem, isto é, a linguagem não verbal, e a insubordinada, linguagem verbal, ou seja, contexto e cotexto. As várias semioses envolvidas na postagem colaboram para o estabelecimento de sentidos por parte do escrevente e do leitor.

13 Sobre os usos de desgarradas no corpus roteiros de cinema, consultem-se os trabalhos de Silvestre e Rodrigues (2014), Rodrigues e Fontes (2018) e Rodrigues e Silvestre (2019). 
- Insubordinação: uma proposta funcionalista para o estudo de (des)articulação de cláusulas

Figura 6. Post com exemplo de circunstancial insubordinada

\section{Quando a fofoca vem com print}

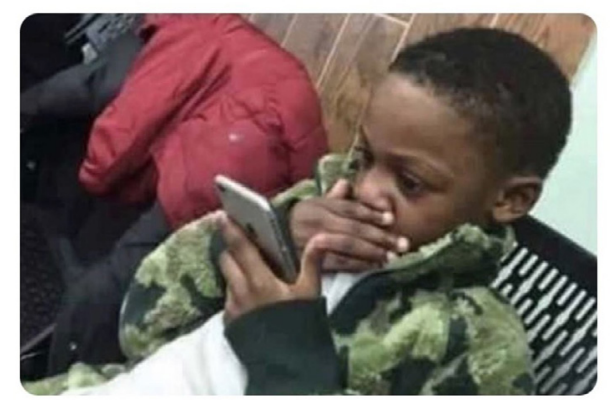

Fonte: Corpus de pesquisa das autoras.

Usos como esses ficariam sem análise, caso não adotássemos o fenômeno da insubordinação e, ainda, se não adaptássemos a noção de desengajamento clausal para a língua escrita das redes sociais. Pelos resultados preliminares de nossas análises, tudo indica que esse uso tem estreita ligação com o gênero meme (cf. CAVALCANTE; RODRIGUES, 2018; RODRIGUES; FONSECA, 2019).

\section{Considerações finais}

As pesquisas a respeito da insubordinação trazem à tona uma nova questão relativa à articulação de cláusulas à medida em que demonstram que as cláusulas subordinadas, fortemente encaixadas em suas principais, estão também sujeitas a percorrer um caminho contrário e a se tornarem sintática e semanticamente independentes. Relativamente aos estudos mostrados neste artigo, o objetivo era traçar as linhas gerais de cada um deles, de modo a apresentar o fenômeno ao leitor iniciante no tema. Desse modo, foram priorizados as explanações e os exemplos, em detrimento da exposição de um número maior de autores.

Adicionalmente, também propusemos uma análise das insubordinadas a partir da proposta de desengajamento clausal de Cristofaro (2016), abordagem ainda inédita em português brasileiro. Essa análise faz parte de uma pesquisa, em curso, realizada pelas autoras, mas que tem trazido resultados interessantes a respeito do tema.

No entanto, é importante deixar claro que ainda há muitos esclarecimentos a serem feitos acerca da insubordinação. Ao que tudo indica, como afirma Cristofaro (2016), ela parece ser resultado de vários mecanismos distintos e que não se relacionam 
exclusivamente a esse fenômeno, como é o caso da reanálise, da extensão e da própria elipse.

Em português brasileiro, é necessário, também, realizar uma investigação diacrônica, a fim de atestar as origens desses usos. Além disso, uma análise prosódica ${ }^{14}$ permitiria perceber com mais clareza o grau de (in)dependência sintática das cláusulas insubordinadas, já que na fala não há o suporte material dos sinais de pontuação. Do mesmo modo, também se pode averiguar a ocorrência do fenômeno na escrita e se determinado gênero textual favorece ou não o uso da insubordinação.

Como se nota, há um vasto campo de exame disponível sobre o tema e muitas respostas a serem dadas por pesquisas futuras. Espera-se que este artigo contribua para instigar novas investigações.

\section{Referências}

BUSCHA, L. A. Isolierte Nebensätze im dialogischen text. Deutsch als Fremdsprache, v. 13, p. 274-279, 1976.

BYBEE, J. Língua, uso e cognição. Tradução Maria Angélica Furtado da Cunha. Revisão técnica Sebastião Carlos Leite Gonçalves. São Paulo: Cortez, 2016.

BYBEE, J.; PERKINS, R.; PAGLIUCA, W. The evolution of grammar. Chicago and London: The University of Chicago Press, 1994.

CAVALCANTE, S. A. de S.; RODRIGUES, V. V.; COAN, M. Sintaxe: articulação de orações. In: LIMA, A. H. V.; SOARES, M. E.; CAVALCANTE, S. A. de S. (org.). Linguística geral: os conceitos que todos precisam conhecer. v. 3. São Paulo: Pimenta Cultural, 20203.

CRISTOFARO, S. Routes to insubordination: a cross-linguistic perspective. In: EVANS, N.; WATANABE, H. (ed.). Insubordination. Amsterdam: John Benjamins Publishing Company, 2016. p. 393-422.

DECAT, M. B. N. Estruturas desgarradas em língua portuguesa: Campinas: Pontes Editores, 2011.

14 Em relação ao desgarramento, análises prosódicas foram feitas por Silvestre e Rodrigues (2017), por Rodrigues e Silvestre (2019) e por Rodrigues e Mallmann (2020). 
- Insubordinação: uma proposta funcionalista para o estudo de (des)articulação de cláusulas

DECAT, M. B. N. Por uma abordagem da (in)dependência de cláusulas à luz da noção de "unidade informacional". Scripta (Linguística e Filologia), Belo Horizonte: PUC Minas, v. 2, n. 4, p. 23-38, 1999.

D'HETERFELT, S. Insubordination in Germanic: A typology of complement and conditional constructions. Berlin/Boston: De Gruyter Mouton, 2018.

EVANS, N. Insubordination and its uses. In: NIKOLAEVA, I. (ed.). Finiteness: Theoretical and Empirical Foundations. Oxford: Oxford University Press, 2007. p. 366-431.

EVANS, N.; WATANABE, H. The dynamics of insubordination: An overview. In: EVANS, N.; WATANABE, H. (ed.). Insubordination. Amsterdam: John Benjamins Publishing Company, 2016. p. 5-35.

GRAS, P. Revisiting the functional typology of insubordination: Insubordinate que-constructions in Spanish. In: EVAN, N.; WATANABE, H. (ed.). Dynamics of insubordination. Amsterdam: Benjamins, 2016. p. 113-144.

HEINE, B.; KALTENBÖCK, G.; KUTEVA, T. On insubordination and cooptation. In: EVANS, N.; WATANABE, H. (ed.). Insubordination. Amsterdam: John Benjamins Publishing Company, 2016. p. 39-64.

HIRATA-VALE, F. B. de M.; OLIVEIRA, T. P. de; SILVA, C. F. da. Construções insubordinadas no português do Brasil: completivas e condicionais em análise. In: Odisseia, Natal, v. 2, n. esp., p. 25-41, 2017.

HOPPER, P.; TRAUGOTT, E. C. Grammaticalization. Cambridge: Cambridge University Press, 1993.

MITHUN, M. Sources and mechanisms. In: BEIJERING, K.; KALTENBÖCK, G.; SANSIÑENA, M. S. (ed.). Insubordination: Theoretical and empirical issues. De Gruyter Mouton: Berlin, 2019. p. 29-54.

MITHUN, M. Shifting finiteness in nominalization: From definitization to refinitization. In: CHAMOREAU, C.; ESTRADA-FERNÁNDEZ, Z. (ed.). Finiteness and Nominalization. Amsterdam: John Benjamins Publishing Company, 2016. p. 297-321. 
MITHUN, M. The extesion of dependency beyond the sentences. Language, v. 84, n. 1, p. 69-119, 2008.

RODRIGUES, V. V. Cláusulas sem núcleo em português: desgarramento ou insubordinação? São Paulo: Blucher, 2021.

RODRIGUES, V. V. O desgarramento de orações completivas no Facebook. In: II SEMINÁRIO DO GRUPO DE PESQUISA CONECTIVOS E CONEXÃO DE ORAÇÕES. Anais do II Seminário do Grupo de Pesquisa Conectivos e Conexão de Orações. Niterói: Faculdade de Letras da Universidade Federal Fluminense, 2019. v. 1, p. 93-112.

RODRIGUES, V. V.; SILVESTRE, A. P. dos S. Desgarramento de cláusulas hipotáticas: interface sintaxe-prosódia. In: FERRAZ, D.; TOMAZI, M. M.; ROCHA, L. H. P. da. (org.). Estudos linguísticos: perspectivas interdisciplinares. Vitória: EdUFES, 2019.

RODRIGUES, V. V.; MALLMANN, A. C. L. G. Orações completivas e completivas desgarradas: comportamento prosódico. Revista de Letras, Fortaleza, v. 2, n. 39, p. 44-55, 2020.

RODRIGUES, V. V.; FONTES, A. M. O desgarramento de orações adverbiais nos roteiros de cinema. In: COELHO, F. A. C.; SILVA, J. E. do N.; CONFORTE, A. N. (org.). Descrição e ensino de Língua Portuguesa: temas contemporâneos. v. 6. Rio de Janeiro: Dialogarts, 2018. p. 615-629.

SILVESTRE, R. de C. P. E.; RODRIGUES, V. V. Cláusulas com para e sua multifuncionalidade. Entrepalavras, Fortaleza, v. 7, p. 93-106, ago./dez. 2017.

SANSIÑENA, M. S. P. The multiple functional load of que: an interactional approach to insubordinate complement clauses in Spanish. 2015. PhD Thesis. Katholieke Universiteit Leuven, Leuven, 2015.

SILVESTRE, A. P. dos S.; RODRIGUES, V. V. O desgarramento de cláusulas comparativas e a interface sintaxe-prosódia. In: XXV Jornada Nacional do Gelne, 2014, Natal - RN. Anais da XXV Jornada Nacional do Gelne. v. 1. Natal: Editora da Universidade Federal do Rio Grande do Norte - EDUFRN, 2014. p. 1-11. 
- Insubordinação: uma proposta funcionalista para o estudo de (des)articulação de cláusulas

COMO CITAR ESTE ARTIGO: BARONI, Gabriela do Couto; RODRIGUES, Violeta Virginia. Insubordinação: uma proposta funcionalista para o estudo de (des) articulação de cláusulas. Revista do GEL, v. 18, n. 3, p. 285-310, 2021. Disponível em: https://revistadogel.gel.org.br/

Submetido em: 25/06/2021 | Aceito em: 01/09/2021. 